\title{
História com maiúscula de um minúsculo inseto
}

\author{
Big story of a small insect \\ Historia con mayúscula de un minúsculo insecto
}

Sílvio Marcus de Souza Correa*

LOPES, Gabriel. O feroz mosquito africano no Brasil: o Anopheles gambiae entre o silêncio e a sua erradicaçâo (1930-1940). Rio de Janeiro: Editora Fiocruz, 2020, 227 p.

Já vai longe o tempo da história dos grandes homens, dos manuais escolares ilustrados com figuras varonis. Nas últimas décadas, o público leitor se acostumou com histórias da vida privada, do cotidiano, das mulheres e de outros atores ou mesmo protagonistas que até então eram vistos como subalternos ou meros coadjuvantes de uma história por demais eurocêntrica. Em 1961, Jean-Paul Sartre anteviu a emergência de novos atores na contemporaneidade ao prefaciar o livro Os condenados da terra, de Frantz Fanon. O filósofo percebeu que os indivíduos do "terceiro mundo" seriam os novos protagonistas de uma história pós-colonial. Alguns anos depois, Emmanuel Le Roy
Ladurie propôs uma história assaz diferente. Ao estudar as oscilaçóes climáticas na longa duração, o historiador contribuiu para relativizar o papel do ser humano e do seu lugar no palco da história. ${ }^{1} \mathrm{Na}$ década seguinte, o balbuciar de uma história ambiental favoreceu novas perspectivas, menos dualistas e mais ecológicas, com ênfase nas complexas interaçóes entre os seres vivos e suas correlaçôes em diferentes ecossistemas (PÁDUA, 2010).

Com o fim das metanarrativas, o papel atribuído aos humanos deixou de ter a primazia no enredo sobre o passado. Não cabe aqui retomar o que François Dosse chamou de "história em migalhas". Basta sinalar a pluralidade ou a multiplicidade de correntes, abordagens e métodos na história desde as

\footnotetext{
${ }^{1}$ A chamada "grande aceleração" do Antropoceno faria rever, mais tarde, o impacto da atividade humana sobre ecossistemas modificados de forma abrupta e profunda a partir da segunda metade do século XX.
}

DOI: http://dx.doi.org/10.1590/2237-101X02204810

Resenha recebida em 10 de agosto de 2021 e aceita para publicação em 16 de agosto de 2021.

* Professor da Universidade Federal de Santa Catarina / Programa de Pós-Graduação Interdisciplinar em Ciências Humanas e PPG em História Global, Florianópolis/SC - Brasil. Bolsista Produtividade CNPq 2. E-mail: silvio.correa@ufsc.br. ORCID: https://orcid.org/0000-0002-0364-6590. 
últimas décadas do século $\mathrm{XX}$ e a possibilidade de pensar uma história sem centro, sem fim em si mesma e livre de determinismos e daquele antropocentrismo dos grandes modelos explicativos. É nesse florido jardim de Clio que o historiador Gabriel Lopes seguiu as marcas de um mosquito desde a sua aparição no Brasil até a sua erradicação.

Aprovada no Programa de Pós-Graduação em História das Ciências e da Saúde da Casa de Oswaldo Cruz (COC/Fiocruz) em 2016, a tese de Gabriel Lopes foi laureada na categoria de Ciências Humanas e Sociais do Prêmio Oswaldo Cruz no ano seguinte e publicada recentemente sob o título $O f e$ roz mosquito africano no Brasil, na coleção História e Saúde da Editora Fiocruz. Em sua apresentação do livro, Jaime Benchimol vaticina que a obra "certamente constituirá a principal referência sobre o assunto". Já Marcos Cueto destaca em seu prefácio que o livro é um exemplo "de que é possível conciliar a história da ciência com a história ambiental". Afirma ainda que o autor desvenda a teia de relaçốes entre "ecossistemas, políticas de saúde e pesquisas médicas locais, nacionais e globais". Difícil acrescentar algo mais ao que já foi apontado com acuidade e autoridade pelos dois pesquisadores da Casa de Oswaldo Cruz.

O título do livro toma de empréstimo a alcunha do "feroz mosquito" dada por Afrânio Peixoto ao Anopheles gambiae. A chegada desse inseto africano ao Nordeste brasileiro coincide com a intensificação das linhas de transportes marítimos e aéreos no "mundo atlântico", o qual já era espaço de disseminação de animais e plantas desde séculos. A in- vasão biológica de espécies exóticas ocorreu nas duas margens do Atlântico e favoreceu o alastramento de patógenos, vetores e doenças tropicais (CURTIN, 1993).

No Caribe, homens e mulheres de origem europeia ou africana pagaram literalmente com seu sangue um pesado tributo aos mosquitos cujo "império" durou mais tempo que qualquer outro naquela regiáo (McNEILL, 2010). Na África tropical, a malária foi um dos principais obstáculos para a conquista militar europeia no final do século XIX. ${ }^{2} \mathrm{Na}$ primeira metade do século $\mathrm{XX}$, ela representa um empecilho à modernização de países como a Argentina e o Brasil. Um agravante foi a dispersão passiva de um vetor da malária no Nordeste brasileiro, tema do livro de Gabriel Lopes.

Em 1930, um navio de aviso precisava apenas de alguns dias para fazer a linha marítima entre Dacar e Natal. Diante da intensificação dos transportes ligeiros transatlânticos, o médico e cientista Adolfo Lutz alertou as autoridades sobre o perigo da entrada de patógenos e insetos transmissores de doenças tropicais pelos portos e aeroportos brasileiros. Não tardou para o entomólogo norte-americano Raymond

\footnotetext{
${ }^{2}$ Para o período da chamada Partilha da África, o historiador William B. Cohen (1983) demonstrou como a redução da mortalidade pelo paludismo no império francês teve mais a ver com a substituição de soldados europeus por africanos durante a expansão militar do que com os avanços da medicina tropical. Por seu turno, Wolfgang U. Eckart (1998) destacou a instrumentalizaçáo da medicina tropical pelo colonialismo alemão em suas campanhas contra a malária. Já Philip D. Curtin (1998) concluiu que os préstimos da medicina tropical tornaram a África mais barata de administrar, mas não mais barata de conquistar.
} 
Shannon identificar nas cercanias da capital do Rio Grande do Norte larvas do Anopheles gambiae, um dos transmissores da malária em regiôes tropicais do continente africano.

$\mathrm{Na}$ introdução do livro, o autor situa o tema no debate historiográfico, mostra a pertinência do assunto e apresenta a sua abordagem em termos teóricos e metodológicos. $\mathrm{O}$ historiador analisa com acribia um corpus documental variado (diários, cartas, relatórios, ofícios, artigos científicos, matérias de jornais etc.) sobre a aparição do Anopheles gambiae e a infestação desse mosquito africano em regióes do Nordeste brasileiro na década de 1930. Aprofunda aspectos da epidemia da malária transmitida pelo inseto invasor que já tinham sido abordados de forma sucinta pela história ambiental (OLIVEIRA, 2012) e mesmo inovadora pela história oral (SILVA, 2012). Tem-se um estado da arte multisciente que revela não apenas desafios do campo interdisciplinar, mas também as vantagens de fazer dialogar a história das ciências e da saúde com a história ambiental e com a história global.

O primeiro capítulo do livro trata da presença inusitada do mosquito africano em terras brasileiras e das açóes emergenciais para combater o inseto invasor entre 1930 e 1932. O segundo capítulo aborda a "invasão silenciosa" do mosquito africano no decorrer da década de 30, quando o Anopheles gambiae fez sua aparição também no Ceará. $\mathrm{O}$ autor recorre a arquivos nacionais e estrangeiros para explorar os caminhos do alastramento do paludismo pelo vetor estrangeiro. No terceiro capítulo, tem-se uma abordagem das epidemias de malária que articula a história da medicina tropical no Brasil com uma história transnacional e regional de políticas de saúde, com ênfase nas açóes da International Health Division (IHD) da Fundação Rockefeller no país e na institucionalização do Serviço de Malária do Nordeste (SMNE) em 1939. No quarto e último capítulo, o autor apresenta controvérsias e impasses das autoridades científicas e analisa estratégias a partir do repertório disponível para a erradicação do invasor africano, bem como o suposto perigo que representava o novo vetor quando a malária tornou-se uma questão central de saúde pública ao final da década de 1930.

$\mathrm{Na}$ tessitura da trama narrativa com os fios da história da medicina tropical, da história ambiental e da história global, alguns pontos aparecem um pouco soltos. Se a invasão biológica de uma espécie exótica é, geralmente, facilitada pela degradação de biomas pela ação antrópica, mister seria identificar as interferências humanas no ambiente onde o Anopheles gambiae invadiu e encontrou condiçóes favoráveis para a sua reprodução. $\mathrm{O}$ regime de chuvas, o clima e a competição ecológica com outras espécies podem ter desempenhado um papel mais importante para a erradicação do mosquito africano no Brasil do que as medidas sanitárias adotadas. Escusado é lembrar que a região Nordeste do país conheceu um dos períodos mais longos de estiagem em meados da década de 30 .

Um ponto controverso reside no indício de exagero nos discursos de autoridades políticas e científicas sobre o risco da propagação do inseto invasor e sobre a importân- 
cia de suas intervençôes para a erradicação do vetor estrangeiro. As divergências entre Evandro Chagas, Bruce Wilson, Fred Soper, Gastão César e outros em relação às estaçôes experimentais do Serviço de Estudos de Grandes Endemias (SEGE), onde havia criadouros de Anopheles gambiae, demonstram os conflitos no interior de uma burocracia marcada pelos poderes emaranhados de funcionários do SEGE, do SMNE e da Fundação Rockefeller. A pesquisa atilada do historiador não permitiu novas ilaçóes sobre a responsabilidade do trabalho experimental com o mosquito africano pelos surtos de malária no Ceará no final da década de 1930. Resta saber se alguns casos não seriam decorrência de eventual falha no controle dos criadouros. O trabalho experimental do SEGE era promissor para a entomologia médica, a epidemiologia e a infectologia, mas não se pode descartar a hipótese de que ele teria feito parte do problema. Comprová-la significa, outrossim, pôr um bemol no tom da narrativa da "infestação silenciosa" do mosquito africano.

Assim como a ecologia do mosquito em novos ambientes, a atuação internacional da Fundação Rockefeller enseja uma perspectiva em história global, notadamente no que tange à sinergia da sua "filantropia científica" com regimes autoritários. Como apontou Jaime Benchimol (2001, p. 125), a Revolução de 1930 havia criado "um quadro político mais propício ao controle verticalizado dos mosquitos e das populaçóes humanas". Cabe ainda lembrar que métodos ofensivos e com substâncias tóxicas para o combate dos anofelinos foram propostos por pesqui- sadores da Fundação Rockefeller e empregados na Itália fascista no final da década de 1920. A Fundação Rockefeller participou também da campanha antipalúdica em Portugal, onde foi construído um Instituto de Malariologia em 1938. No ano seguinte, Francisco Cambournac foi nomeado diretor do referido instituto, sendo responsável pelo plano de campanha sanitária que erradicou a malária naquele país no início da década de 1940. O nome de Cambournac esteve também associado à luta contra a malária em Cabo Verde. Nota-se que a Fundação Rockefeller foi o principal agente financiador externo para as campanhas de erradicação da malária no Brasil e em Portugal sob os respectivos governos de Vargas e Salazar.

A Fundação Rockefeller participou também da luta contra a malária na Índia e na ilha de Chipre, quando ambas as regióes ainda estavam sob domínio colonial britânico. Nessa última colônia, o epidemiologista cipriota Mehmet Aziz empregou um método ofensivo para erradicaçáo dos mosquitos que fez a campanha sanitária parecer uma campanha militar (CONSTANTINOU, 1998) $)^{3}$.

A propalada erradicação do mosquito africano no Brasil se inscreve numa utopia científica que seria a resposta para aquela visão do país como um "imenso hospital”. $\mathrm{Na}$ verdade, era toda a região

${ }^{3}$ Em 1935, a Fundação Rockefeller se interessou pelo problema da malária em Chipre. As principais espécies de mosquitos da ilha eram dois anopheles (A. superpictus e A. elutus). Em 1946, a "Anopheles Eradication Campaign" teve início. Em 1948, a campanha abrangeu toda a ilha e, no ano seguinte, foi anunciada a conclusão dos trabalhos.

${ }^{4}$ O Brasil como um "imenso hospital” foi uma ex- 
tropical que tinha uma representação estigmatizada, o que servia para aumentar o efeito da propaganda colonial na África a partir dos serviços de "assistência médica aos indígenas" e dos discursos higienistas e sanitaristas na América do Sul de meados do século XX. A combinação entre ideias higienistas e racistas não se verificava apenas nos espaços coloniais. No Brasil da Primeira República e do Estado Novo, a medicina tropical propôs alguns planos e métodos de ações profiláticas que nada diferem daqueles empregados na África colonial. Na Argentina, o combate à malária entre 1937 e 1949 e sob os auspícios da Fundação Rockefeller foi outro exemplo de medidas verticais sob uma população estigmatizada por discursos higiênicos e eugênicos (CARTER, 2012).

Se a perspectiva transnacional permite encontrar similaridades entre as profilaxias antimaláricas levadas a cabo no Brasil e alhures nas décadas de 1930 e 1940, a compreensão das particularidades históricas exige ter em conta a sobreposição de realidades locais, regionais e nacionais. Ao articular os distintos planos de análise, Gabriel Lopes logra um conhecimento complexo e de referência para os futuros estudos sobre o tema.

Os atuais processos de "globalização" de plantas e animais introduzem novos

pressão usada pelo médico Miguel Pereira num discurso realizado na Faculdade de Medicina do Rio de Janeiro em 1916. A mesma figura de linguagem foi usada por Charles Issawi quando comparou o Vale do Nilo a um "hospital gigante". Aliás, a África foi vista como um "grande laboratório" à época dos impérios coloniais (TILLEY, 2011). atores na história do tempo presente, o que favorece novas abordagens sobre as interações entre seres humanos e não humanos, sobre a capacidade de adaptação e de resistência de patógenos e vetores e sobre as pesquisas científicas para controle biológico, para medicamentos fitoterápicos e mesmo para vacinas num mundo cada vez mais suscetível a pandemias. Com o auxílio da microbiologia, da infectologia e da modelagem climática, pode-se prever alguns efeitos do aquecimento global. O clima de um futuro próximo pode facilitar a transmissão de vírus por mosquitos no Brasil (LORENZ et al., 2017). Além disso, doenças endêmicas (virais, bacterianas e parasitárias) podem lograr uma disseminação "globalizada" no século XXI. Matéria não vai faltar para a história de arboviroses e outros microorganismos como fungos, bactérias e protozoários ultrarresistentes. Nos últimos anos, a invasão de novos mosquitos tem sido registrada na Europa, como o Aedes albopictus, transmissor de patógenos de moléstias como a zika, chikungunya e dengue, e na África oriental, como o Anopheles stephensi, principal vetor da malária na Índia. Ao mesmo tempo, plantas medicinais como a Artemisia annua são transplantadas e cultivadas no mundo inteiro, notadamente para fins profiláticos e terapêuticos contra a malária. ${ }^{5}$

\footnotetext{
${ }^{5}$ No Brasil, estudos com a planta Artemisia annua L. são realizados no Centro Pluridisciplinar de Pesquisas Químicas, Biológicas e Agrícolas (CPQBA) da Universidade Estadual de Campinas (Unicamp) desde 1988. Cf. Ereno (2005).
} 
O livro de Gabriel Lopes sobre um minúsculo inseto é como um caleidoscópio nas mãos de quem se interessa pela história ambiental, pela história global, pela história das ciências e da saúde ou simplesmente pela História com inicial maiúscula. Essa última não significa uma "história total" no sentido braudeliano, nem aquela das grandes narrativas, mas uma história em que tudo se mescla e seres humanos e não humanos se encontram em coevolução e podem vir a ser personagens de um mesmo enredo. Numa paráfrase ao título de um famoso ensaio de Spivak, Timothy Mitchell (2002) perguntou se "pode um mosquito falar"? O livro O feroz mosquito africano no Brasil contém uma resposta instigante.

\section{Referências}

BENCHIMOL, Jaime L. Febre amarela: a doença e a vacina, uma história inacabada. Rio de Janeiro: Editora Fiocruz, 2001.

CARTER, Eric D. Enemy in the blood. Malaria, environment and development in Argentina. Tuscaloosa: The University of Alabama Press, 2012.

COHEN, William B. Malaria and French imperialism. The Journal of African History, v. 24, n. 1, p. 23-36, 1983.

CONSTANTINOU, Kate. Malariabekämpfung aufZypern von den Anfängen unter Britischer Kolonialherrschaft bis zur "Eradication". Dissertation (Medizinische Fakultät) Ruprecht-Karls-Universität Heidelberg, 1998.

CURTIN, Philip D. Disease and empire. The health of European troops in the conquest of Africa. New York: Cambridge University Press, 1998.

CURTIN, Philip. Disease exchange across the tropical Atlantic. History and Philosophy of the Life Sciences, v. 15, n. 3, p. 329-356, 1993.

ECKART, Wolfgang U. Malaria and Colonialism in the German Colonies New Guinea and the Cameroons. Research, control, thoughts of eradication. Parassitologia, v. 40, n. 1/2, p. 83-90, 1998. ERENO, Dinorah. A terapia da artemísia. Medicamento contra a malária derivado de planta chinesa será produzido no Brasil. Revista Pesquisa, FAPESP, n. 118, p. 68-71, dez 2005.

LOPES, Gabriel. O feroz mosquito africano no Brasil: o Anopheles gambiae entre o silêncio e a sua erradicação (1930-1940). Rio de Janeiro: Editora Fiocruz, 2020.

LORENZ, Camila et al. Impact of environmental factors on neglected emerging arboviral diseases. PLoS Negl Trop Dis, v. 11, n. 9, e0005959, 2017. Disponível em: https://doi.org/10.1371/ journal.pntd.0005959.

McNEILL, John R. Mosquito empires: ecology and war in the Greater Caribbean, 1620-1914. Cambridge: Cambridge University Press, 2010.

OLIVEIRA, Eveli D. Anopheles gambiae e Aedes aegypti: a "invasão" do Brasil o irromper de epidemias. In: CORREA, Sílvio M. de S. (org.) Bioses africanas no Brasil: notas de História Ambiental. Itajaí: Casa Aberta, 2012. p. 173-194. 
PÁDUA, José Augusto. As bases teóricas da História Ambiental. Estudos Avançados, São Paulo, v. 24, n. 68, p. 81-101, 2010.

SILVA, Gláubia C. A. S. Epidemia de malária no Ceará: enredos de vidas, mortes e sentidos políticos (1937-1942). Tese (Doutorado em História) - Programa de Pós-Graduação em História da Universidade de Pernambuco, Recife, 2012.
TILLEY, Helen. Africa as a living laboratory: empire, development, and the problem of scientific knowledge, 1870-1950. Chicago: University of Chicago Press, 2011.

MITCHELL, Timothy. Rule of experts: Egypt, techno-politics, modernity. Berkeley: University of California Press, 2002. 